\title{
A descriptive, qualitative study of the challenges that individuals with Autism Spectrum Disorder experience when transitioning from skills training programs into the open labor market in Cape Town, South Africa
}

\author{
Mogammad Shaheed Soeker* \\ Department of Occupational Therapy, University of the Western Cape, Cape Town, South Africa
}

Received 10 March 2019

Accepted 18 January 2020

\begin{abstract}
.
BACKGROUND: There is limited existence of qualitative research on adults with Autism Spectrum Disorder (ASD), who are transitioning between skills training programs and finding employment in the open labor market, in South Africa.

OBJECTIVE: The aim of this current study was to explore the experiences and perceptions of individuals living with ASD, regarding transitioning from a skills training program to working in the open labor market.

PARTICIPANTS: The data were collected through semi-structured interviews with ten participants, who were diagnosed with ASD, and working in the open labor market, as well as five key informants, who have worked with autistic individuals in a skills training program.

METHODS: The data collected, using an explorative, descriptive, qualitative method, were analyzed using thematic analysis, and resulted in three emerging themes.

RESULTS: Theme one: The 'disorder' in the workplace - The individual and collective barriers that individuals experience in the workplace are described, including social, emotional, and communication difficulties, as well as the stigmatization experienced by persons with a disability. Theme two: Making the workplace work - The facilitative support that individuals are exposed to, in the form of intervention from occupational therapists, sensory psychologists, and other forms of skills training programs, are described. In addition to supportive intervention, the relationships and networking within, and outside of the workplace, are discussed in theme two. Theme three: What works for me - The individual adaptations made by the participants, in the form of unique coping mechanisms in the workplace, as well as in the home environment, are discussed. CONCLUSION: It was observed that, while there are barriers to the transitioning of autistic individuals into the open labor market, there are enablers that facilitate a less challenging transitioning process, in the form of family and workplace support, as well as skills training, and self-identified coping mechanisms.
\end{abstract}

Keywords: Return to work, adaptation, coping skills and strategies, adaptation, vocational rehabilitation

\section{Introduction}

*Address for correspondence: Mogammad Shaheed Soeker, Private Bag X17, Bellville 7535, South Africa. Tel.: +27 021959 9339; Fax: +27 021959 1259; E-mail: msoeker@uwc.ac.za.

According to Fletcher-Watson and Happé [1], ASD is a lifelong developmental disorder, which is charac- 
terized in individuals with atypical behaviors in social interactions, social communication and social imagination. The strengths identified in individuals with ASD include exhibiting high intelligence; displaying a special talent; being creative; demonstrating a good memory; being musically or artistically talented; achieving high performance in mathematics; and presenting a loving, focused and determined nature. However, the challenges identified include poor academic achievement; communication; social interactions; behavior; understanding the feelings of others; being understood by others; coping with change in routine; being independent within society; and difficulty concentrating [2]. Although no specific study exists on the prevalence of ASD in sub-Saharan Africa, Kakooza-Mwesige et al. [3] in their study that focused on the Kenyan population indicated that the prevalence of individuals diagnosed with ASD was increasing, and is estimated at $1.2 / 100-1.3 / 100$ of the total population.

Work for individuals with ASD could contribute to an improvement in their quality of life [4], as it allows them to engage in routine, as well as interaction with a variety of people, with whom they would usually not interact. In a study conducted by Mason et al. [5], which focused on the predictors of quality of life for individuals with ASD, the findings revealed significant positive predictors of QoL for being employed (physical QoL), receiving support (social and environment QoL), and being in a relationship (social QoL). The findings of a systematic review completed by Abubakar, Ssewanyan and Newton [6], as well as a scoping review conducted by Franz, Chambers, von Isenberg and de Vries [7], did not reveal a single study that focused on Adults living with ASD in sub-Saharan Africa (including South Africa). However, they did identify a strong need for large-scale research programs, to improve the quality of life of individuals living with ASD. Being employed in the open labor market (OLM) (competitive employment) could be viewed as a measure to improve an individual's quality of life, particularly, when they can earn a salary. Hedley, Uljarevic, Bury and Dissanayake [8] in a study that focused on predictors of mental health and well-being in employed adults living with ASD, the study's results did indicate that apart from a slight increase in daily living skills that there was a slight decrease in job satisfaction among the study participants. However their measure of mental health and well-being remained stable over time, thus indicating that despite individuals being dissatisfied with their jobs that their well-being remained stable.
Employment in the open labor market, in the South African context, implies working in the competitive labor market with other able-bodied individuals. In the OLM, finding employment is challenging for individuals with ASD, because of the lack of support in the workplace. There appears to be a breakdown at the point of transitioning. Therefore, it is evident that there is a need to explore the experiences of adults with ASD, regarding their transitioning into the open labor market, particularly from a South African context. The findings of such a study could assist in developing programs that would support skills training, to address the challenges that individuals with ASD experience, when entering the OLM.

\subsection{Literature review}

\subsubsection{Transitioning}

The transition from school to adulthood could be especially challenging to individuals with ASD, as well as their families [9]. The South African education system includes schools for children with special needs, including physical disability and intellectual impairment. In addition, the South African government has also introduced skills schools that focus on technical skills, such as those required to perform tasks such as, mechanical repairs, carpentry, and electrical work, to name a few. These schools enable learners with disability to be integrated with learners without disability. However, depending on the severity of the physical or intellectual impairment, learners may still be placed in special schools, which provide additional support that caters to their needs.

The skills obtained in skills schools may assist the learner with ASD to find employment in the open labor market, or competitive employment, and, depending on the severity of the individual's functional impairments, they could pursue studies at a university, or participate in sheltered employment, and/or protective workshops. Usually, in these protective workshops, individuals with ASD may be employed to do simple tasks, such as packaging, or assembly line activities. Despite being ambitious about finding employment, individuals with ASD commonly experience poor transition outcomes, including finding employment [10], limited opportunities to participate in further education [11], and low rates of independent living. Poor work and educational outcomes are experienced across the lifespan for those with ASD, who display average or above average intellectual capacities [12]. It could be argued that the above outcomes could be, or at 
least in part, the result of the limited availability of appropriate, affordable services, as well as the lack of appropriately trained professionals, who are available to this population, as they transition into adulthood [13].

\subsubsection{Barriers and facilitators related to employment}

One of the main barriers related to the employment of individuals living with ASD, is the low employment rates observed globally, which could be attributed to factors at individual and environmental level. At individual level, the barriers to maintaining employment includes poor social communication and interpersonal skills $[14,15]$. Barriers at environmental level includes the stigma that society places on the functional limitations of the individual with ASD, instead of focusing on their abilities [16].

Facilitatory factors include individual, environmental, or context specific facilitators, and aspects of work that facilitate employment. Individual facilitators include having insight into personal strengths and weaknesses, as well as possessing skills related to a specific job [17]. Environmental facilitators include the network of supportive people, namely, coworkers, family and friends; diversity training among co-workers and staff; customized workplace accommodations; and ongoing support [18].

\subsubsection{Adaptation strategies}

In the workplace, these adaptation strategies ranged from individualized workplace accommodations, during which professionals, such as job coaches, work alongside the adult with ASD, through the initial weeks of work, as well as during the course of the employment, to help with the maintenance of employment $[19,20]$. These workplace supports may range from access to an on-site job coach (for example, the monitoring of the quality of the individual's work), and supports for workplace participation (for example transportation to the work site) [21].

\subsubsection{The importance of work for individuals with ASD}

Work could be described as the productive engagement of an individual, which includes employment interest, employment seeking, job performance, volunteer exploration and participation [22]. Skills development is an important part of work. Skills include becoming well informed, and learning how to network with community organizations, which may be resources to employment. Individuals with ASD are often regarded as the group of persons with disabilities, most likely to be unemployed due to the social interaction demands [19]. It has been determined that individuals with ASD embody characteristics of a high degree of accuracy in visual perception, concentration, memory, and a tolerance for repetitive tasks [21]. However, it is still observed that their lack of forming social relationships, as well as their atypical social behaviors, hinder them from experiencing work as an occupation, and gaining the skills, by engaging in an occupation [21]. Employers and management need to practice flexibility in adapting skills, and be willing to provide accommodations, which is crucial for the success for individuals with ASD in the workplace [23]. Effective management of individuals with ASD is important when deciding on which support intervention is applicable, and the most beneficial to the employee with ASD, as well as how it affects their job performance [23]. According to Hagner and Cooney [21], supervisors of individuals with ASD expressed the importance of being direct and specific, when offering advice, assigning new tasks, and providing explanations to individuals with ASD. In this current study, therefore, the researchers explore the perspectives of individuals with ASD, and key informants (health therapists), regarding transitioning into competitive employment.

\subsection{Aim}

To explore the experiences and perceptions of individuals living with ASD about transitioning from a skills training program to the open labor market.

\subsection{Objectives}

1. To explore the experiences and perceptions of individuals living with ASD about the barriers and facilitators that affect them when transitioning from a skills training program into the OLM.

2. To explore adaptation strategies utilized by individuals living with ASD in maintaining their worker role.

\section{Method}

\subsection{Methodological approach}

Qualitative researchers study topics in natural settings, interpreting phenomena in terms of the significance people attach to them [24]. This current study was positioned in the socio-constructive paradigm, specifically using an exploratory descrip- 
tive research design. An exploratory research design allows for the exploration of an individual's personal perspectives, and the descriptions of their experiences on the topic of enquiry, without the manipulation of the research participants involved [25]. Employing a descriptive approach, allowed the researchers to develop a detailed understanding of the lived experiences of the participants involved, through the explanation and interpretation of the collected data. In a study conducted by Humphrey and Symes [26], the authors utilized qualitative research methodology to explore the experiences of pupils with ASD regarding bullying and social support in the school setting. Their study reinforced the importance of using a qualitative approach, particularly if the aim is to reduce the anxiety among individuals living with ASD, when seeking in-depth information on a particular research topic. In this current study, an exploratory approach enabled the researchers to gather detailed information about the coping strategies used by individuals with ASD, who were transitioning into competitive employment.

\subsection{Population and sampling}

Eight participants (i.e. individuals diagnosed with ASD) were purposively sampled from the statistical records of the Occupational Therapy Departments of Psychiatric Hospitals in Non-Governmental Organizations (NGOs), as well as protective and sheltered workshops in the Western Cape, South Africa. The researchers also included five key informants who were qualified occupational therapists. Purposive sampling was used, because the researchers aimed to explore the specific experiences of individuals, currently living with a diagnosis of ASD, having successfully transitioned into the open labor market employment, after rehabilitation. This sampling strategy was important because the researchers wanted to explore the experiences of individuals, who had transitioned to working in the OLM, specifically. The majority of individuals, living with ASD in the South African context, are dependent on a government disability grant; therefore, many do not seek employment in the OLM. The inclusion and exclusion criteria are set out in Appendix A.

The researchers focused more on the functional ability of the participants, and did not restrict individuals, who had intellectual disability, as well as Marfan syndrome, and worked in the open labor market, from participating in the study. The exclu- sion criteria, therefore, were adjusted. In addition, the researchers focused on including participants in the age group of 18-55 years in this current study, as this is the recognized economically active age group in South Africa. From a gender perspective, seven of the participants were male, and three were female, mainly from the White classified racial group, with only one participant classified as Colored. According to Population and Registration Act of 1950, the Colored racial classification is defined as individuals with mixed racial ancestry, for example, descendants from Black, Asian and White racially classified parents [27]. Although the researchers made every effort to include participants from various racial backgrounds, it was mainly participants, classified as white, who consented to participate in this current study. For the purpose of the current study is has to be mentioned that the racial classification of black, could also be viewed as the collective term used to describe individuals from the Coloured and Indian racial group. Also, that the black racial group is the majority population in South Africa.

In terms of age, the majority (70\%) of the participants were in the age group of 30-45 years. Five of the participants were employed in administrative-related jobs, and five in manual- or semi-manual-related occupations. Six of the participants had a tertiary level of education, while four had a high school level of education. At the time of this current study, nine of the participants were employed in the open labor market (competitive employment), and one was employed in the open labour market and later on in a sheltered employment type of position. Regarding their socioeconomic context, all of the participants originated from an average, to above-average socio-economic background (average to above-average middle-class). According to Visagie [28], the average middle-class household income could be described as between 5600 and 40000 South African Rands per month (the equivalent to US\$378-US\$2 705).

\subsection{Data collection}

The researchers were occupational therapists, who conducted semi-structured interviews with each of the ten participants, including the five key informants (See Appendix A). The researchers were qualified occupational therapists, who have completed postgraduate qualifications, specifically, in the area of conducting qualitative research, which includes methods of preparing and conducting interviews with 
research participants. The principle investigator, has achieved a $\mathrm{PhD}$ degree, and has conducted several qualitative research projects.

The researchers had no prior contact with the participants. The names of the participants were obtained from the statistical records of NGOs, as well as protective/sheltered employment workshops. In addition, the researchers used social media, to invite the prospective participants to become involved in this current study. For example, an advert about the recruitment of participants was placed on a popular South African Autism website. The health therapists and managers at the NGOs and protective/sheltered employment workshops contacted the participants and informed them about the study, and subsequently, the participants were encouraged to contact the researchers themselves.

When the prospective participants contacted the researchers, the requirements of the study were described in detail. It has to be noted that they received no financial compensation for their participation. The researchers used a semi-structured interview guide, with questions relevant to the study subject, to direct the interviews (Appendix B). The researcher piloted the semi-structured interview guide with two participants. The researcher had a detailed discussion regarding the appropriateness of the research questions and probes especially after it was piloted. The researcher then concluded that the questions were appropriate and understandable to the participants. During each interview the researcher would get the opinion of the interviewees regarding the appropriateness of the interview questions and probes.

The data gathering occurred at a place that was mutually convenient to both the researchers and the participants, namely, the participant's homes, and places of employment. However, the interviews with the key informants was conducted at their places of employment. The researchers prepared the interviewee for the interview by building a relationship, while explaining the study beforehand, to help the participant to relax and be comfortable. The interviews were conducted with ten participants and five key informants, until data saturation was achieved, when the same information, related to the experiences of individuals living with ASD, as well as the key informants, yielded the same concepts. This was determined after the second interview with each participant. All the participants were provided with a summary of the main findings, via email, as well as telephonically. In addition, they were allowed the opportunity to discuss any challenges they might have had, regarding the accuracy of the data.

\subsection{Data analysis}

The researchers used the Tesch [29] data analysis method, which follows eight steps for effective analysis. In step one, the researchers read the transcripts carefully and wrote their thoughts in the margins. In step two, they documented the prominent points, referred to as codes. When this was completed for all the documents, the researchers made a list of topics, also referred to as sub-categories. In step three, these topics were grouped into columns, identified by their themes. In the context of this current study, three themes emerged. In step four, the researchers abbreviated the topics as categories, and subsequently, placed them alongside the appropriate segments of the text.

For steps five through to eight, the researchers decided on the most descriptive wording to entitle the categories, which became the names of the topics. Thereafter, the researchers grouped certain categories in order to avoid any repetition of categories and sub-categories. In the last step of data analysis, the researchers reviewed the data, and double-checked to determine whether any new categories and themes emerged. The researchers read and analyzed each transcript, independently, according to the methods described by Tesch [29]. Subsequently, they met as a group to reach consensus on the themes, categories and sub-categories. The researchers dealt with discrepancies by discussing each transcript in-depth, before deciding, collectively, on the best descriptions for the themes, categories and sub-categories.

\subsection{Trustworthiness}

Strategies such as credibility, transferability, dependability and confirmability are used to ensure the trustworthiness of the data [30]. Credibility was ensured by the thick description of the lived experiences of the research participants. Credibility was also enhanced by triangulation. Triangulation was ensured by the use of more than one source of collecting data, for example, in this current study, participants living with ASD, as well as the key informants. Transferability was ensured by the detailed description of the research methods, contexts, and the lived experiences of the participants. Dependability was ensured by means of dense descriptions, peer examination, and triangulation. The study was documented in such a manner that the readers 
would be able to follow an audit trail. Confirmability was ensured by the process of reflexivity, as the researcher's own biases, or assumptions, were revealed in a reflexive journal. The study was approved by the Institutional Review Board of the University of the Western Cape, under the ethics number $\mathrm{BM} / 17 / 5 / 9$

\section{Findings}

\subsection{Theme One: The 'disorder' in the workplace}

Theme one was characterized by the many workrelated barriers that were expressed in different forms and environments. These barriers negatively influenced the ability of individuals with ASD to engage in tasks, and be understood. Due to these perceived misunderstandings, the dynamics in the workplace were affected, negatively, and social relationships were compromised. The barriers are explored in the following categories.

\subsubsection{Category 1.1: Social, emotional and communication challenges negatively affecting the worker role}

The category of social, emotional and communication challenges emerged from all the participants and key informants, emphasizing the difficulties, individuals living with ASD experience, when communicating with co-workers in their social relationships and dealing with emotions. This, ultimately, influenced their capacity to function and cope, when transitioning and adapting to their worker roles. One of the key informants described communication as a primary barrier, as follows:

"...so I would say their communication [is a primary barrier] but also obviously their integration of information. Their ability to understand exactly what you are saying and then to execute it, and also to continue executing that same task." (K1)

One participant explained that her meltdowns were affected by social, emotional and communication difficulties experienced at home and in the workplace. Her meltdowns negatively affected one of her colleagues, which caused her more distress. The following excerpt refers:

"He has PTSD from my meltdowns so if I have a meltdown or close to it now it triggers in him something which he can hardly cope with um, it's that bad and something which it's no... he doesn't feel he wants to go get sorted out. It's something like, I must sort this part of myself out to not trigger him, which I don't think is necessarily all that fair, even though I caused this, but, it's not something that I could help cause and we both need help now." (P2)

\subsubsection{Category 1.2: Challenges in the work environment}

The work environment was identified as a factor that had a great influence on the work performance of the individual with ASD, as well as her his coping in the workplace. The elements of the work environment that were emphasized as important by the participants and key informants were physical and sensory factors, job tasks, flexibility and problem solving. The participants expressed that there were certain job tasks that they could, or could not do; therefore, if challenges are accommodated for, accommodation fatigue should also be considered. Accommodation fatigue can be described as the extent to which someone could perform workrelated tasks, after adaptations and accommodations have been made. The following excerpts refer:

"...there's lots of things that I can do that none of my colleagues can do um, not even vaguely as well as I can, but there are a lot of very mundane things um, which they can all do which I can't do at all." (P2)

"There's also the issue of accommodation fatigue from an autistic person's point of view um or autistic burnout which is like - you can make a person who's wearing a prosthetic leg, you can make them walk up and down stairs, they can do it and they will do it well for a while but it takes more effort for them to do it than it does for someone with two normally functioning legs. So you have to recognize that it takes more effort to accommodate for that. You know if you don't put in a lift then at least give them a bit more time to walk up and down the stairs." (P1)

In the following excerpt, a key informant clarified what some of the aspects were that needed to be considered, in terms of the stimuli related to the sensory and physical environment, when making accommodations for the specific needs of individuals with ASD in the work environment:

"We'll put him on the job and see how he does because there's all sorts of things to take into 
account: what is the terrain like, how many people are in the environment, what's the noise level, how much distractions is there in the environment. All of those factors, we'll see the effect of that [on the autistic individual]." (K1)

\subsection{Theme Two: Making the workplace work}

The participants expressed various sources, as well as forms of satisfaction and support, which facilitated the maintenance of standards in the workplace. These were not only workplace supports, but support systems and networking in the family, society and professional contexts. This theme is described further in the following categories.

\subsubsection{Category 2.1: Skills Training Programs: \\ "It helps me grow"}

The category of skills training programs, which includes schooling, occupational therapy intervention, training centers, sheltered employment, and psychiatry, were regarded as enablers to autistic individuals, when transitioning into the open labor market. These participants expressed their positive feelings towards skills training at a training center, as well as how these facilitated their transition, and supported their coping in the workplace:

"Well I found that when I was with the living link (NGO that offers skills training), I learnt that you have to be... I learnt to be confident; I learnt to have a positive attitude." (P3)

"Finally, someone that understands me [referring to psychiatrist]." (P4)

The key informants and participants identified skills taught in the training centers that aided the participants to function more effectively in the open labor market. The participants identified the training as beneficial, when transitioning into the workplace. One participant explains, in the following excerpt, how job sampling (allowing the client to do the actual work in the workplace) helped him to understand how the business works:

"I had to do a little bit of Job sampling to learn how exactly the business will work." (P3)

\subsubsection{Category 2.2: Relationships and networking can facilitate the adaptation to the worker's role}

The category about relationships and networking emerged because, unanimously, family support, social interaction, and support from colleagues at work, were perceived as crucial. It was clear that all forms of relationships were essential, to enable individuals with ASD to cope in the open labor market. One participant disclosed how she found her 'fit' by meeting other autistic people, as well as how this made a difference in her life. The following excerpts refer:

"So it was from that colleague, she had the "aspy" husband, anyway I got to know other autistic people then I finally got myself a fit." (P2)

"In the long run it was other autistic people, or people online and so on, um, who made the most difference to my ability to self-optimise." (P2)

Another participant considered that families should engage in practices, which help them to understand ASD, to aid relationship building, and increase the capacity of family members to support people with ASD. The following excerpt refers:

' $Y$ a, also counselling for parents whose children are autistic-particularly non-verbal, just to try help them to get to understand, you know, like if the kid is upset and they insist that the parent mimics them and then they get violent, you know, what is going through the kid's mind; so to kind of help them understand it, um, ya." (PI)

\subsection{Theme Three: "What works for me"}

In this theme, the researchers explored the personal coping mechanisms and contingencies, which the participants introduced over time, after discovering that they were beneficial. Adaptations are specific to the individual, and present within the work, social, and home environments. The following categories describe the theme, further.

\subsubsection{Category 3.1: Self-identified coping mechanisms help an individual to cope in the work environment}

Many of the participants were diagnosed with ASD in their later years, after having progressed through school by that time, with some even working in the open labor market for many years. One of the participants explained how adapting the work environment for autistic individuals could help them to work more productively throughout the day; however, this may not make sense to an individual without ASD, which, 
again, emphasizes that coping mechanisms and adaptations are unique to individuals, depending on what is required. The following excerpt refers:

"It doesn't have to be pretty like here, that's not the point if you have a broom cupboard and you only give the person this space and only their chair can fit in and only the desk that's all that they have and it looks really really terrible and they closing a cupboard door and they sitting inside this little cupboard, it's fine, it's better than having to be out there and having the glitzy shiny desk where you cannot actually operate what so ever, so, you know like if I go into the toilet to stim and I' $m$ sitting there on a cold tiled floor, it's like oh shame you know no, not oh shame, it's fine, it really, it's better than you saying to me be out here in the lunchroom, um, and that, because that's the difference between coping and not coping." (P2)

Another participant expressed how he chose to seek advice and assistance from his employers, or superiors, when struggling to cope in the work environment. The following excerpt refers:

"...But also if there was a situation, I would talk to one of the living link instructors." (P3)

A key informant explained that, in their workplace, when an individual experiences anxiety, or unfavorable conditions, they are encouraged to take some time-out, by visiting the restroom. The following excerpt refers:

"We say that they must go out. If they finding that there is anxiety that is causing it then they must go to the bathroom because no one is really gonna say no unless it happens every hour, then we've got a problem." (Kl)

\subsubsection{Category 3.2: Self-learning and sharing of information related to $A S D$}

The category of self-learning was evident during the interviews. The participants, who were diagnosed later in life, and held a better understanding of what they were experiencing, and lacking in their lives, took the initiative to teach and inform themselves. One participant explained how knowing what benefits an individual with ASD, and sharing this with the ASD community is constructive, as related in the following excerpt:

"So it is also other people's accommodations which they've made, it is also self-knowledge of knowing what kinds of...and we share stims as well so amongst my friends we would be like oh this stim works really well and have you tried that and so on and in the broader sense of stimming some people play video games and that might allow them to especially if they've had conflict with other people then you go off and you play your video game, so after conflict I would often do something like Facebook or whatever because then I can just focus on one thing as opposed to the million things that are bombarding me. those things, ya those things, help, it is part of it getting your sensory things sorted out." (P2)

\section{Discussion}

In this section the researcher will discuss the barriers and facilitators as it relates to the return work process of individuals living with ASD. There will also be a discussion with regard to how the individual living with ASD adapts to their worker role.

\subsection{Barriers to return to work}

When transitioning into the open labor market, the identified barriers include social, emotional, and communication challenges; stigmatization and challenges with social appropriateness and workplace culture.

\subsubsection{Social, emotional and communication challenges negatively affecting the worker role}

According to Strickland, Coles and Southern [31], the main challenges that individuals with ASD face, are in communication, social perception, cognitive and social skills. Parr, Hunter and Ligon [32] state that individuals with ASD may have increased levels of stress and anxiety, and could be overwhelmed easily, because of not knowing when, or how to approach, and interact with work colleagues, when asking for help, as well as which topics are appropriate to discuss in the workplace. One participant discussed an occasion, when she consciously made an effort to be socially appropriate in the workplace, by maintaining eye contact with a client; however, this was interpreted as an inappropriate gesture by the client, instead of a reflection of her interest in the topic, and level of engagement. 


\subsubsection{Stigmatization and workplace culture}

Another barrier identified was that of stigmatization and misunderstanding in the workplace. The participants expressed how they often felt misunderstood by society, including colleagues and superiors in the workplace. This could lead to feelings of stigmatization, as well as a sense that society does not recognize their strengths and abilities, or may even regard them in a different way after their diagnosis. It also became evident that the participants could not comprehend office politics and dynamics easily. An unsupportive work place often creates an environment that may not allow the individual with ASD to maintain employment. Hendricks [31] elaborates on encouraging employers to focus on the capabilities of individuals with ASD, instead of their potential negative behaviors. In addition, Hendricks [33] indicates that the provision of ASD awareness training to employers, could assist the person with ASD adapt to their worker role, ultimately affecting the individual's workplace culture.

\subsection{Facilitators to return to work}

When transitioning into the open labor market, the facilitators identified include intervention in the form of OT and sensory psychology; skills training programs; family and colleague support that facilitates several occupational roles.

\subsubsection{Skills Training Programs: "It helps me grow"}

Skills training programs, which include schooling, occupational therapy intervention, training centers, sheltered employment and psychology, are regarded as enablers to autistic individuals, when transitioning into competitive employment. In training centers, people with ASD are given the opportunity to engage in job sampling, and acquire skills in specific areas [34]. There is currently a void in the literature that focuses on skills training programs; instead, the focus is on how occupational therapists could adapt the working environment, to suit the needs of the individual with ASD better. Nicolas et al. [35] report limited employment support services that include skills training services, as well as limited information about the effectiveness of these services. According to Capo [36], occupational therapists could help to coach coworkers and supervisors in the work environment, to understand the unique traits of an individual with ASD, better, as well as how the environment could be adapted, or compensatory strategies implemented in the workplace. A participant described how he was referred to an occupational therapist for an assessment in order to determine whether he could be reasonably accommodated in the workplace due to his disability. Once referred to the OT, he explained how he was assisted to develop a plan that was beneficial for him, in the form of the disability unit/insurer paying for someone to assist him, or just by having his day scheduled.

\subsubsection{Family and colleague support that facilitates occupational roles}

Due to the limited support services that are often available to individuals with ASD, families are often responsible for the provision of care and the support of children [37]. It could be argued that this type of support is often continued when the individual seeks employment, after completing schooling. Hendricks [33] highlights that employment success for people with ASD, are often dependent on the support of employers, and co-workers. This support could be in the form of flexibility about the way work tasks of individuals with ASD are performed, or being tolerant during supervision. The authors indicate that there is a need to be aware of, as well as understand ASD. In this current study, it was evident that the employees with ASD could succeed in the workplace, because of external support that they received from family and work colleagues.

\subsection{Adaptation to the worker role}

\subsubsection{Self-identified coping mechanisms help an individual to cope in the work environment}

The participants identified that 'stimming' was an important coping strategy for them throughout the day. 'Stimming' is more commonly known as 'stereotypic behavior'. Motor stereotypes are defined as suppressible, repetitive, rhythmical, coordinated, purposeless, fixed, and non-functional patterned movements, which may occur frequently over the course of a day, and/or may present simultaneously [36]. The collection and manner of movement for each ASD individual, is specific to that individual. More than one type of stereotype are usually seen at any given time. In the work environment, factors, such as stress, anxiety, boredom, sensory isolation, social demands, and fatigue, could be experienced, and therefore, increase the probability of stereotypes occurring to an individual with ASD in the work setting [38]. The participants expressed their insight into 'stimming', by disclosing how they used it, effec- 
tively, during the working day. They admitted to using "stimming" more frequently, when under stress (for example, when transitioning into the open labor market and adapting to a new work environment).

Van Jaarsveld [39] states that individuals with ASD engage in self-stimulatory behavior to, either compensate for limited input, or avoid overstimulation. The participants acknowledged that 'stimming' could be perceived as disruptive behavior, and have taken the initiative to find their own space and time to do it. However, in order for 'stimming' to be regarded as beneficial, Hagner and Cooney [21] consider it crucial that employers practice flexibility, and provide accommodations, to enable individuals with ASD to perform work tasks in the workplace. Employers need to consider these self-identified coping mechanisms, when being flexible in their workplace accommodations. A key informant supported this suggestion by explaining that no one in the workplace, who is informed about ASD, would object to autistic individuals engaging in a practice, which helps them to cope, provided it is not disruptive to the other employees.

\subsubsection{Self-Learning and sharing of information related to $A S D$}

One participant shared how he had avoided going to the food court at lunchtime, because he realized that it was too noisy for him, which relates to dealing with changes in the environment. Another participant explained how, often during a meeting, she would close her eyes, and respond with ' $\mathrm{mm}$ ' to indicate that she was listening, when the sensory information of the environment became overwhelming. The participants also disclosed that they would inform their colleagues, beforehand, when they sensed a situation arising, during which they might need to 'stim', or use a coping mechanism, which might not be considered socially appropriate.

Soeker $[40,41]$, in a study conducted with individuals who had sustained Traumatic Brain Injury, argues that occupational therapists could create a supportive environment, by acting as mediators between employers, employees and individuals with TBI, who are employees in the workplace. Similarly, this

Table

Describing the demographics of participants: ASD (South African participants)

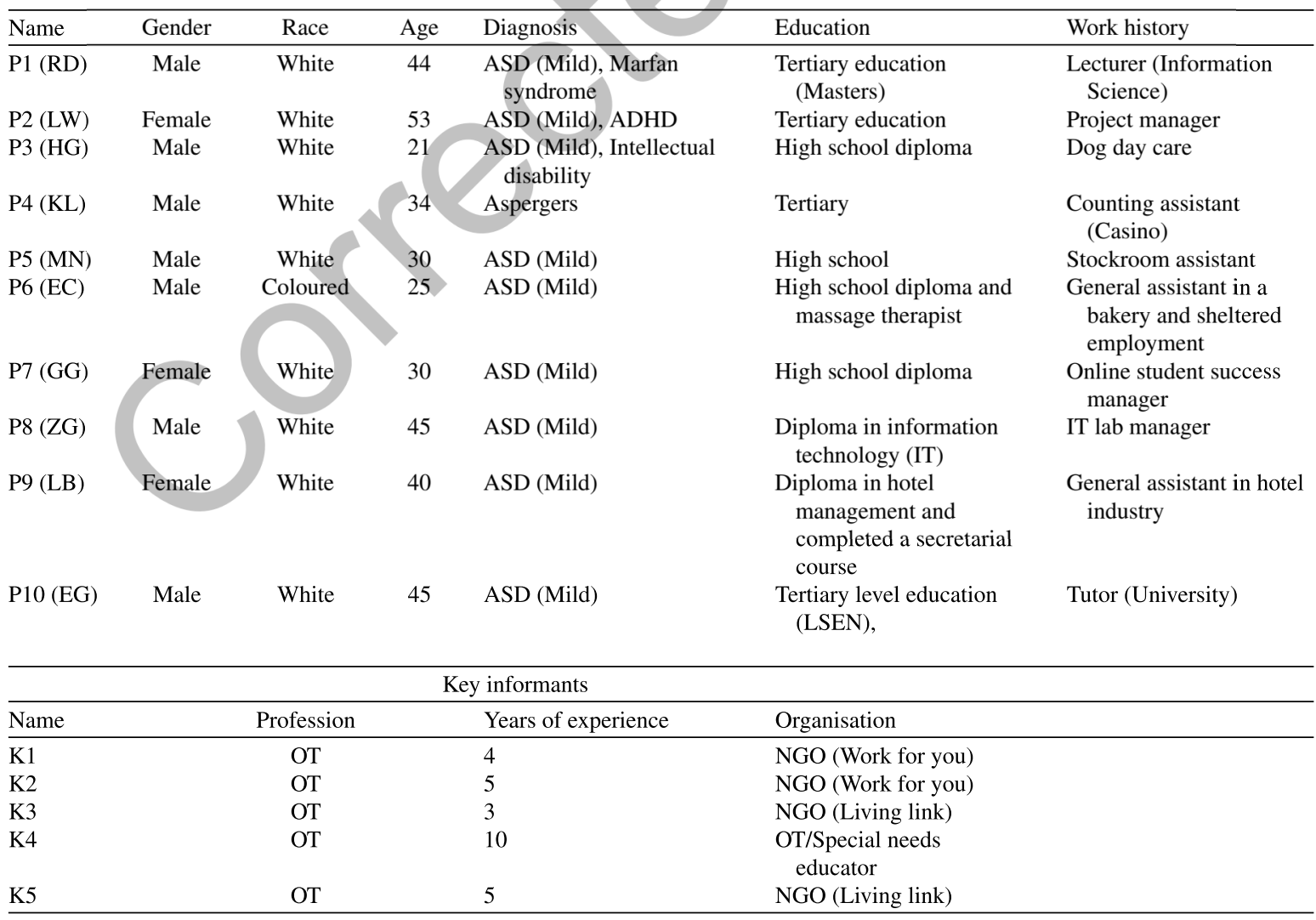


Table 2

Themes and categories

Theme one: The 'disorder' in the workplace

Theme three: "What works for me"
Category 1.1: Social, emotional and communication challenges negatively

affecting the worker role

Category 1.2: Challenges in the work environment

Category 2.1: Skills Training Programs: "It helps me grow"

Category 2.2: Relationships and networking can facilitate the adaptation to the worker's role

Category 3.1: Self-identified coping mechanisms help an individual to cope in the work environment

Category 3.2: Self-learning and sharing of information related to ASD supportive environment could relate to developing strategies, such as adapting the work tasks, instructions, and work routines of individuals with ASD.

\subsubsection{Relationships and networking can facilitate the adaptation to the worker's role}

In the work and social environment of the participants, it emerged that relationships and networking among fellow employees, as well as familial and social relationships, aided growth in the occupational roles of individuals with ASD, as well as the ability to cope during the transition to the work environment and worker role. Research has revealed that friendships at work could enhance employee attitudes towards their job satisfaction, job commitment, and organizational support [42]. One participant spoke about finding her 'fit' in the work environment, as well as how networking with other autistic people made a difference in her ability to self-optimize, and ultimately, fulfill her worker role.

\section{Limitations of the study}

One major limitation is the fact that only males participated in this current study. Another limitation is due to ASD, particularly among people living with ASD, who are employed; it was very difficult to recruit the sample of 10 participants, who met the inclusion criteria of the study. The fact that the majority of the participants in the study were of the white racial group in a country where the black racial population is the majority, could be seen as a limitation of the study. Another general limitation of qualitative research is that the findings provide an exploration of a particular phenomenon, and therefore, does not lend itself to generalisation, due to the smaller sample sizes that are used in qualitative research.

\section{Conclusion}

Both the participants and the key informants emphasized the stigmatization experienced by people with ASD. The stigmatization that individuals living with ASD experience in the workplace is one of the major barriers, which increases their anxiety, when returning to work. The study findings suggest that the participants were ambivalent about disclosure of the various stereotypical behaviors, which they engaged in, especially in the workplace. However, the 'stimming' or stereotypical behavior is observed as one of the main methods, used to calm individuals with ASD in the workplace. The fact that some employers were not aware of the behavioral concerns related to ASD could be viewed as a possible barrier for RTW.

Some of the participants indicated that a stronger support system in the workplace could be established by enhancing the knowledge about ASD among employers and co-workers. This current study identified some of the barriers that prevent individuals living with ASD from adapting to the work environment; however, one of the facilitatory factors identified was a need for the provision of good quality vocational rehabilitation programs. These factors may improve the reintegration of individuals diagnosed with ASD into jobs in the open labor market.

\section{Implications for practice}

- Supportive employment as a form of workplace reintegration should be implemented as part of traditional vocational rehabilitation programs.

- Job sampling and work test placement were seen as supportive to vocational rehabilitation programs.

- Regular workshops should be conducted by professionals, or individuals involved in skills 
training for individuals with ASD, with employers about the skills that individuals with disability have to offer, and facilitate regular communication sessions with the employer, coworkers and individuals with ASD. This process would help minimise the stereotypes related to the employment of individuals with ASD.

\section{Conflict of interest}

The author declares no potential conflicts of interest with respect to the research, authorship, and/or publication of this article.

\section{Acknowledgments}

This study was made possible with the financial support of the University of the Western Cape and Missouri University (USA). The researcher would also like to thank the Occupational Therapy students and Ms Zakeera Ganie who assisted in collecting data for the study.

\section{References}

[1] Fletcher-Watson S, Happé F. Autism: A New Introduction to Psychological Theory and Current Debate Edition 2nd Edition. London Imprint Routledge. 2019. DOI https://doi.org/10.4324/9781315101699

[2] American Psychiatric Association. Diagnostic and statistical manual of mental disorders: DSM-5. Washington, D.C: American Psychiatric Association; 2013.

[3] Kakooza-Mwesige A, Ssebyala K, Karamagi C, Kiguli S, Smith K, Anderson MC, Grether JK. Adaptation of the "ten questions" to screen for autism and other neurodevelopmental disorders in Uganda. Autism. 2014;18(4): 447-457.

[4] Rosqvist HB, Keisu BI. Adaptation or recognition of the autistic subject? Reimagining autistic work life: Deconstructing the notion of "real jobs" in the Swedish autistic self-advocacy movement. Journal of Vocational Rehabilitation. 2012;37(3):203-212.

[5] Mason D, McConachie H, Garland D, Petrou A, Rodgers J, Parr JR. Predictors of quality of life for autistic adults. Autism Res. 2018;11(8):1138-1147.

[6] Abubakar A, Ssewanyana D, Newton CR. A systematic review of research on Autism Spectrum Disorders in subSaharan Africa. Behavioural Neurology. 2016; Article ID 3501910:14 pages. https://doi.org/10.1155/2016/3501910.

[7] Franz L, Chambers N, von Isenburg M, de Vries PJ. Autism spectrum disorder in sub-Saharan Africa: A comprehensive scoping review. Autism Research. 2017;10: 723-749.

[8] Hedle D, Uljarevic M, Bury SM, Dissanayake C. (2019) Predictors of mental health and well-being in employed adults with autism spectrum disorder at 12-month followup. Autism Research. 2019;12(3):482-494

[9] Meiring M, Seabi J, Amod Z, Vorster A, Kern A. Transition for adolescents with autism spectrum disorder: South African parent and professional perspectives. Frontiers in Psychiatry. 2016;7;7:93.

[10] Taylor JL, Seltzer MM. Employment and post-secondary educational activities for young adults with autism spectrum disorders, during the transition to adulthood. J Autism Dev Disord. 2011;41(5):566-74.

[11] Shattuck PT, Narendorf SC, Cooper B, Sterzing PR, Wagner M, Taylor JL. Postsecondary education and employment among youth with an autism spectrum disorder. Pediatrics. 2012;129(6):1042-1049.

[12] Taylor JL, Mailick MR. A longitudinal examination of 10year change in vocational and educational activities for adults with autism spectrum disorders. Developmental Psychology. 2014;50(3):699-708.

[13] Shattuck PT, Wagner M, Narendorf SC, Sterzing PR, Hensley M. Post-high school service use among young adults with an autism spectrum disorder. Archives of Pediatrics and Adolescent Medicine. 2011;165(2):141-146.

[14] Brownlow C. Presenting the self: Negotiating a label of autism. Journal of Intellectual \& Developmental Disability. 2010;35(1):14-21.

[15] Gal E, Landes E, Katz N. Work performance skills in adults with and without high functioning autism spectrum disorders (HFASD). Research in Autism Spectrum Disorders. 2015;10:71-77.

[16] Lorenz T, Frischling C, Cuadros R, Heinitz, K. Autism and overcoming job barriers: Comparing job-related barriers and possible solutions in and outside of autismspecific employment. PLoS One, 2016;11(1):e0147040. https://doi.org/10.1371/journal.pone. 0147040

[17] Gal E, Ben Meir A, Katz N. Development and reliability of the Autism Work Skills Questionnaire (AWSQ). American Journal of Occupational Therapy. 2013;67(1): e1-e5. https://doi.org/10.5014/ ajot.2013.005066.

[18] R. Hudson, The effect of brief training on attitudes and interactions of co-workers of individuals with autism [doctoral dissertation]. 2004. Retrieved from ProQuest Dissertations $\&$ Theses Global (Order No. 3164641).

[19] McDonough JT, Revell G. Accessing employment supports in the adult system for transitioning youth with autism spectrum disorders. Journal of Vocational Rehabilitation. 2010;32(2):89-100.

[20] Westbrook JD, Nye C, Fong CJ, Wan JT, Cortopassi, T, Martin, FH. Employment assistance services for persons with Autism Spectrum Disorders effects on employment outcomes. St. Louis, MO., USA: Federal Reserve Bank of St Louis; 2012.

[21] Hagner D, Cooney BF. "I do that for everybody": Supervising employees with Autism. Focus on Autism and other developmental disabilities, 2005; 20(2): 91-97.

[22] McNaughton D, Richardson L. Supporting positive employment outcomes for individuals with autism who use AAC. SIG 12 Perspectives on Augmentative \& Alternative Communication. 2013;22(3):164-172. https://doi.org/10.1044/aac22.3.164.

[23] Ha DH, Page JJ, Wietlisbach CM. Work evaluation and work programs. Pedretti's Occupational Therapy-E-Book: Practice Skills for Physical Dysfunction, St Louis, Mosby; 2013.

[24] Denzin N. The sage handbook of qualitative research. 3rd ed. California, USA: Sage Publications; 2005. 
[25] Lambert, VA, Lambert CE. Qualitative descriptive research: An acceptable design. Pacific Rim International Journal of Nursing Research. 2012;16(4):255-256.

[26] Humphrey N, Symes W. Responses to bullying and use of social support among pupils with autism spectrum disorders (ASDs) in mainstream schools: a qualitative study. Journal of research in Special Educational Needs. 2010;10(2):82 90.

[27] South African Population and Registration Act, Act 30 of 1950. Available from: http://www.statssa.gov.za.

[28] Visagie J. Who are the middle class in South Africa? Does it matter for policy? 2013. Available from: http://www.econ3x3.org/sites/default/files/articles/Visagie\% $202013 \% 20$ Middle \%20class\%20FINAL_0.pdf.

[29] Tesch R. Qualitative research: analysis types and software tools. Bedford, England, United Kingdom: LSL Press Ltd. 1990;9-19.

[30] Krefting, L. Rigour in qualitative research: The assessment of trustworthiness. American Journal of Occupational Therapy. 1991;45(3):214-222

[31] Strickland DC, Coles CD, Southern LB. Job TIPS: A transition to employment program for individuals with autism spectrum disorders. Journal of Autism and Developmental Disorders. 2013;43(10):2472-2483.

[32] Parr AD, Hunter ST, Ligon, GS. Questioning universal applicability of transformational leadership: Examining employees with autism spectrum disorder. The Leadership Quarterly. 2013;24(4):608-622.

[33] Hendricks D. Employment and adults with autism spectrum disorders: Challenges and strategies for success. Journal of Vocational Rehabilitation, 2010;32(2):125-134

[34] Miralles C, Marin-Garcia JA, Ferrus G, Costa AM. OR/MS tools for integrating people with disabilities into employ ment. A study on Valencia's Sheltered Work Centers for Disabled. International Transactions in Operational Research. 2010;17:457-473

[35] Nicholas DB, Zwaigenbaum L, Zwicker J, Clarke M, Lamsal R, Stoddart KP, Carroll C, Muskat B, Spoelstra M, Lowe $\mathrm{K}$. Evaluation of employment-support services for adults with autism spectrum disorder. Autism. 2018;22(6):693702.

[36] Capo LC. Autism, employment, and the role of occupational therapy. Work, 2001;16(3):201-207.

[37] Schlebusch L, Samuels AE, Dada S. South African families raising children with autism spectrum disorders: Relationship between family routines, cognitive appraisal and family quality of life. Journal of Intellectual Disability Research. 2016;60(5):412-423.

[38] Ghanizadeh A. Clinical approach to motor stereotypes in Autistic children. Iranian Journal of Pediatrics. 2010;20(2):149-159.

[39] Van Jaarsveld A. Sensory integration in mental health. In Crouch R, Alers VM. Occupational therapy in psychiatry and mental health. 5th ed. Chichester, West Sussex, England, United Kingdom: John Wiley \& Sons, 2014; page range.

[40] Soeker MS, Darries Z. Challenges women with traumatic brain injury experience in their work environment after vocational rehabilitation. Work. 2019;64:477-486.

[41] Soeker MS, Ganie Z. The experiences of employers and care givers of individuals returning to work through the use of the Model of Occupational Self Efficacy for returning brain injured individual to work. Work. 2019;64:355-370.

[42] Patricia O. Improving interpersonal relationships in work places. Journal of Research and Method in Education. 2015;5(6): 115-125 


\section{Appendices}

Appendix A: Inclusion and Exclusion Criteria

\section{Inclusion criteria:}

- The participants need to be $18-55$ years of age

- Must have been employed in the open labor market for a period of 6-12 months

- The participants must be able to communicate in either English or Afrikaans

- The participants must be classified in the mild classification of ASD (the number and type of symptoms can differ drastically and range from mild to severe. Symptoms fall into a range of categories, including problems with social interaction, perseveration and somatosensory disturbance. This is also known as level 1 autism, they have mild symptoms and may not require much support Mayes \& Calhoun, 1999)

\section{Exclusion criteria}

- Individuals with any other co-morbid conditions in conjunction with ASD, such as physical and mental impairments and psychiatric diagnosis will be excluded

\section{Key informants}

Below are the inclusion criteria pertaining to the Occupational Therapists used for this study:

- The key informant will be an occupational therapist with at least 6 months' experience in providing rehabilitative intervention with individuals with ASD

- The key informants need to have experience of working in the field of vocational rehabilitation

\section{Appendix B: Interview guide: Participants}

1. Could you describe to me how you cope in your work environment?

Probe: Describe what you do when you are in a stressful situation?

2. What factors within your working environment makes it difficult for you to cope?

Probe: What are the things that you find makes your job unpleasant?
3. Can you describe the support that you have when you feel that you are struggling to cope within your work environment?

Probe: How do you make use of these supports? What type of support assists you within your workplace and at home?

Do you feel you receive the support you need to cope within your workplace and at home?

4. Now that you have completed skills training and returned to work, can you describe how you have adapted to your work?

Probe: Please describe how your role as a worker has been affected?

Please describe your confidence in terms of overcoming the challenges in your job?

Please describe your view of seeking another job in the open labor market?

5. Can you think of any ways that the skills training program that you participated in could be improved so that others attending it would be able to better adapt to working in the open labor market?

Probe: Can you describe how the skills training that you received helped you to cope better within your work environment?

\section{Interview guide: Key informants}

1. Could you describe the main barriers and facilitators that affect the individual with ASD`s work skills when working in the OLM

Probe: Describe the barriers and facilitators that specifically relates to individuals with ASD in maintaining employment.

2. Could you describe the components of a skills training program that helps facilitate the integration of individuals living with ASD in the OLM?

Probe: Describe how you determine what needs to be focused on for your clients in order to find employment?

Describe how your rehabilitation differs from client to client?

3. Please describe how your skills training program prepares the individual with ASD to find employment in the OLM?

Probe: What aspects of the program is important to enable individual 's living with ASD ability to maintain employment?

Probe: How does it help the client to adapt to the work environment? 
4. How does working with the specific symptoms of ASD differ from that of another diagnosis and would you say it has an influence on their work performance?

Probe: can you explain how ASD affects an individual's work performance?
5. Can you think of any ways in which the skills training program that you facilitate, could be improved or expanded so that more individuals with ASD could benefit?

Probe: School programs, programs in hospitals/protective workshops and in the workplace? 